pretation of a variety of nuclear phenomena are described in chapters on the electromagnetic properties of nuclei, alpha and beta decay, the nuclear photo-effect and mu-mesic atoms. The discussion of these latter topics is relatively brief and no attempt is made to review the current experimental situation or to survey the literature, although a substantial bibliography is given.

The text is clear and the format is attractive, but the number of diagrams is quite surprisingly small considering that the subject is one which lends itself to pictorial representation more readily than many other branches of nuclear theory. It is not quite clear what level of readership is aimed at. Postgraduate students and others new to the subject may find that some effort and reference to original papers are necessary to work through the book completely, but those with some knowledge of the subject may well find it one of the most enjoyable works on nuclear models currently available.

DAPHNE F. JACKSON

\section{DALTON'S ACHIEVEMENTS}

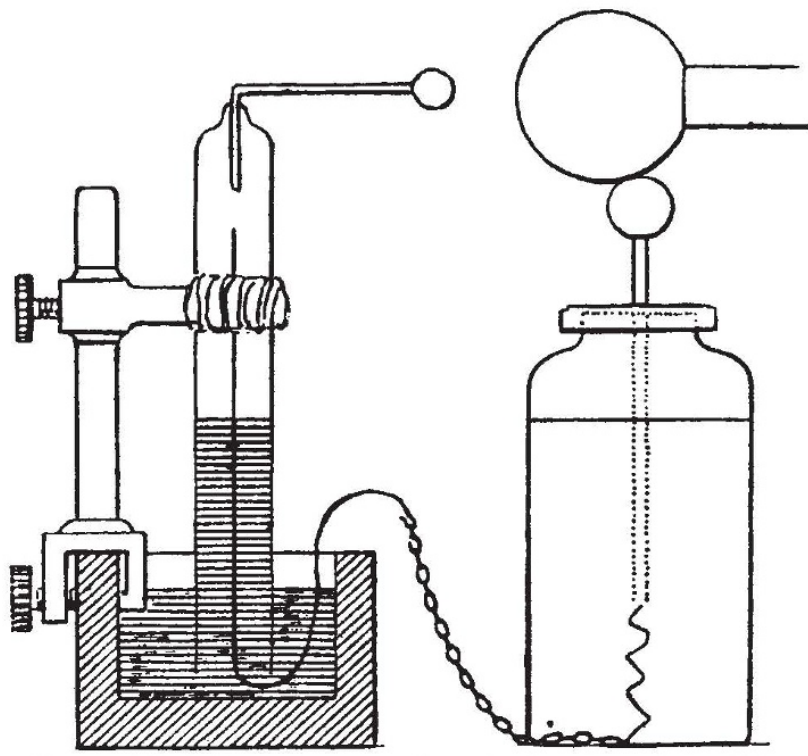

Type of Volta's eudiometer described and used by John Dalton. This is one of several pieces of scientific apparatus used by Dalton described by Kathleen R. Farrar in a paper presented to a conference held in Manchester in 1966 to mark the bicentenary of Dalton's birth. This and the other papers have now been published in a volume edited by $D$. S. L. Cardwell, John Dalton and the Progress of Science (Manchester University Press: Manchester, 55s).

\section{THEORY OF SOLIDS}

\section{Solid State Physics}

An Introduction to its Theory. By Hylton Clark. Pp. vii +240 . (Macmillan: London; St Martin's Press: New York, 1968.) $40 s$.

THE author has set out to write an elementary textbook dealing with the material basic to a more advanced course in solid state physics. It is a book designed to meet the specific needs of undergraduate and first year research students. It seems a pity that this fact could not have been more clearly expressed in the title. The level of the book is quite different from those with similar titles and this, together with the set of well-thought-out problems that appear at the end of each chapter, makes for a fairly unique text.

Chapters 1, 2, 5 and 6 discuss the role of the electrons in solids. The material here, though perfectly standard, is quite clearly presented and with the minimum of ". . . it can be shown that . . .". There are two chapters which deal with the lattice; the cohesive properties of the principal types of solid are covered in the seventh chapter. Throughout the book, there is great emphasis on the fundamental property of crystalline solids; namely, the existence of a regular crystal lattice. Thus the third chapter is about elementary group theory and it is a useful introduction to the more advanced texts on the subject. Obviously, there are topics which the author has omitted and which individual readers will feel should have been considered. I would like to have seen the idea of electron screening in metallic crystals more explicitly discussed (the passing reference to it in chapter 7 is rather misleading). On the whole, however, the selection of material to be included has been wisely made.

There are several places where a closer contact with experiment would have improved the book. The theory of solids, which really consists of a series of judicious approximations, has always developed hand in hand with experiment. "Metals are plastic ... " asserts the author in the seventh chapter, forgetting to point out that many metals become brittle at low temperatures. Again, although the nearly free electron theory is adequately treated mathematically, the surprising success of this relatively crude model in describing the electron states of a variety of metals is not brought out at all. A reference to the underlying reasons behind this success would have been very welcome at this point.

But, in spite of this criticism, this book must surely be counted a success and the author is to be congratulated on producing a well-written introduction to what is, after all, a difficult subject.

J. E. Enderbi

\section{NEW FRONTIERS}

\section{Kinetics in Analytical Chemistry}

By Harry B. Mark, jun., and Garry A. Rechnitz. (Chemical Analysis: a Series of Monographs on Analytical Chemistry and its Applications, Vol. 24.) Pp. xi +339. (Interscience (Wiley): London and New York, August 1968.) $160 s$.

DURING the past decade there has undoubtedly been an explosion of new ideas, methods and techniques in the traditionally conservative area of analytical chemistry. Many new physico-chemical procedures have come to the fore, and, in the area of traco analysis in particular, it may now be more appropriate to talk of analytical science rather than chemistry. It is certainly true, however, that the sensitivity and specificity of these trace methods are such that many reaction rates can now be monitored by them to a degree not previously possible. Thus reaction kinetics can bo pressed into scrvice for analytical chemistry as well as the equilibrium methods used before. This use of dynamic systems opens out many new possibilities. For example, many isomeric compounds show little difference in reactivity under equilibrium conditions but may react at very different rates so that differentiation is easily possible.

The role of kinetically based analytical procedures in analytical chemistry is the subject matter of this new book - the first in the field. The book is essentially concerned with the kinetics of slow reactions and their analytical implications. It first of all discusses methods for the measurement of reaction rates based on changes in concentration, temperature, solvent or ionic strength and deals with mixing methods, sprung and periodic methods. and so on. This is followed by chapters on kinetic methods for catalysed and uncatalysed reactions. A large section follows on the kinetic resolution of mixtures of closely related compounds and another on the basis of determining mixtures or organic compounds by differential reaction rate methods. Finally, the text makes a full and detailed assessment of the value of using analytical reactions based 